\title{
High Molecular Weight Kininogen Binds to Unstimulated Platelets
}

\author{
Ellen J. Gustafson, Darlene Schutsky, Linda C. Knight, and Alvin H. Schmaier \\ Department of Medicine, Hematology/Oncology Section, Thrombosis Research Center, Temple University Health Sciences Center, \\ Philadelphia, Pennsylvania 19140
}

\begin{abstract}
Studies were performed to determine if the unstimulated platelet membrane has a site for high molecular weight kininogen (HMWK) binding. ${ }^{125} \mathrm{I}-\mathrm{HMWK}$ bound to unstimulated platelets. $\mathrm{Zn}^{++}$was required for ${ }^{125} \mathrm{I}-\mathrm{HMWK}$ binding to unstimulated platelets and binding was maximal at $50 \mu \mathbf{M ~ Z n ^ { + + }}$. Neither $\mathbf{M g}^{++}$ nor $\mathrm{Ca}^{++}$substituted for $\mathrm{Zn}^{++}$in supporting ${ }^{125} \mathrm{I}-\mathrm{HMWK}$ binding to unstimulated platelets, and neither ion potentiated binding in the presence of $50 \mu \mathrm{M}$ zinc. ${ }^{125} \mathrm{I}-\mathrm{HMWK}$ competed with equal affinity with HMWK for binding, and excess HMWK inhibited ${ }^{125}$ I-HMWK-platelet binding. Only HMWK, not prekallikrein, Factor XII, Factor XI, Factor V, fibrinogen, or fibronectin inhibited ${ }^{125}$ I-HMWK-platelet binding. ${ }^{125} \mathrm{I}-\mathrm{HMWK}$ binding to unstimulated platelets was $89 \%$ reversible within 10 min with a 50-fold molar excess of HMWK. Unstimulated platelets contained a single set of saturable, high affinity binding sites for ${ }^{125}$ I-HMWK with an apparent dissociation constant of 0.99 $n M \pm 0.35$ and 3,313 molecules/platelet \pm 843 . These studies indicate that the unstimulated external platelet membrane has a binding site for HMWK that could serve as a surface to modulate contact phase activation.
\end{abstract}

\section{Introduction}

The contact phase of plasma proteolysis consists of the zymogens, Factor XII, and prekallikrein (PK), ${ }^{1}$ and the cofactor, high molecular weight kininogen (HMWK). Initiation of contact proteolysis is believed to be due to the binding of Factor XII to negatively charged surfaces where autoactivation of Factor XII occurs, converting it to an active serine protease (1-11). Nonphysiologic substances with a negative surface charge that activate Factor XII include kaolin, celite, glass, dextran sulfate, and ellagic acid (12). The physiologic activator(s) of the system is still unknown. Proposed substances have included crude collagen (13), sulfatides $(14,15)$, and glycosaminoglycans (16).

Platelets have been proposed as a negatively charged surface for contact activation. Platelets contain a form of HMWK (17) and platelet HMWK is expressed on the external platelet mem-

Address correspondence to Dr. Schmaier, Dept. of Medicine, Thrombosis Research Center, Temple University Health Sciences Center, 3400 N. Broad St., Philadelphia, PA 19140. 1986.

Received for publication 8 April 1985 and in revised form 13 March

1. Abbreviations used in this paper: ELISA, enzyme-linked immunosorbent assay; HMWK, high molecular weight kininogen; PADGEM, platelet activation-dependent granule-external membrane; $\mathrm{PGE}_{1}$, prostaglandin $\mathrm{E}_{1} ; \mathrm{PK}$, prekallikrein.

J. Clin. Invest.

(c) The American Society for Clinical Investigation, Inc.

0021-9738/86/07/0310/09 \$1.00

Volume 78, July 1986, 310-318 brane after thrombin activation (18). This latter finding suggests that the platelet membrane has a site for HMWK binding. Investigations by Greengard and Griffin (19) have indicated that HMWK specifically binds to activated platelets. If HMWK only binds to activated platelets, then the participation of platelets in contact activation could never be a primary event in intrinsic coagulation. It would only result as a consequence of platelet activation and thrombin formation. Alternatively, if it were shown that platelets that have not been activated by exogenous agonists, which we will call unstimulated platelets, contain a high affinity receptor for HMWK, then platelets could be a surface to modify intrinsic coagulation. A study was initiated to determine whether unstimulated platelets possess a binding site for HMWK. The results of this investigation show that a specific, high affinity binding site for HMWK is present on the unstimulated platelet surface.

\section{Methods}

Materials. Human alpha thrombin $(3,209 \mathrm{NIH} \mathrm{U/mg)} \mathrm{was} \mathrm{obtained}$ from Dr. J. Fenton, New York State Department of Health, Albany, NY. ${ }^{125} \mathrm{I}-\mathrm{Na}(50 \mathrm{mCi} / \mathrm{mmol})$ was obtained from New England Nuclear, Boston, MA. Iodogen (chloroamide, 1,3,4,6-tetrachloro-3 alpha, 6 alphadiphenylglycoluril) was obtained from Pierce Chemical Co., Rockford, IL. $N$-butyl-phthalate was obtained from Fisher Scientific Co., Pittsburgh, PA. Chelex 100 was purchased from Bio-Rad Laboratories, Richmond, CA. Apyrase was prepared by the method of Molnar and Lorand (20), and stored at $-70^{\circ} \mathrm{C}$ until used. Heparin was obtained from Elkins-Sinn, Inc., Cherry Hill, NJ. Purified Factor XI $(600 \mu \mathrm{g} / \mathrm{ml})$ was a gift from Dr. Peter Walsh; Factor XII $(68 \mu \mathrm{g} / \mathrm{ml})$ and Factor V $(1 \mathrm{mg} / \mathrm{ml})$ were obtained from Dr. Robin Pixley and Dr. Robert Colman; and fibrinogen $(17 \mathrm{mg} / \mathrm{ml})$ and fibronectin $(1.3 \mathrm{mg} / \mathrm{ml})$ were donated by Dr. Andrei Budzynski; all of Temple University, Philadelphia, PA. Apiezion oil (a mixture of silicon oils) was obtained from Apiezion Products Limited, London, England. All other materials were obtained from Sigma Chemical Co., St. Louis, MO and were the best grade commercially available.

Plasma and platelets. Pooled normal plasma (lot N 10) was purchased from George King Biomedical, Inc., Overland Park, KS. Total kininogendeficient plasma (plasma deficient in both HMWK and low molecular weight kininogen) and platelets were donated by Mrs. M. Williams, Philadelphia, PA. Prekallikrein-deficient plasma was donated by Dr. Charles Abiligard, University of California at Davis. Normal donors were young males and females (age 21-45 yr) receiving no medication, who had given their written informed consent. Fresh blood was collected and platelet-rich plasma and platelet-poor plasma were prepared as previously described (21).

Proteins. HMWK was purified using a modified method (18) of Kerbiriou and Griffin (22) which included $0.2 \mathrm{M}$ epsilon amino caproic acid in all buffers and $2 \mathrm{mM}$ diisopropylfluorophosphate added to the pooled material before each step. This preparation of HMWK on a $7.5 \%$ polyacrylamide gel with sodium dodecyl sulfate (SDS) on reduced gel electrophoresis (23) was mostly a single band of 120,000 molecular weight (mol wt) with $>98 \%$ purity (Fig. 1) and with a specific activity of 12-20 $\mathrm{U} / \mathrm{mg}$. In some experiments a partially cleaved preparation of HMWK was used which contained $70 \%$ single-chain HMWK $(120,000 \mathrm{~mol} \mathrm{wt})$ and $30 \%$ two-chain HMWK $(64,000$ and $47,000 \mathrm{~mol} \mathrm{wt})$, as determined from densitometer scans (SD 3000 Spectrodensitometer; Schoeftel In- 


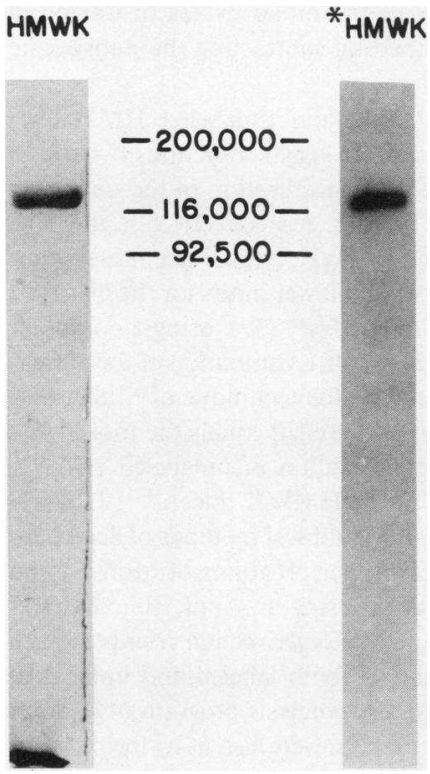

Figure 1. Polyacrylamide gel electrophoresis SDS of HMWK. Gel on left (HMWK) represents $10 \mu \mathrm{g}$ of purified HMWK stained with Coomassie Blue R-250. Gel on right $\left({ }^{*} \mathrm{HMWK}\right)$ represents ${ }^{125} \mathrm{I}$ HMWK autoradiogram after gel electrophoresis in SDS. The gels represented were run in an acrylamide concentration of 7.5 in the presence of SDS after the sample was reduced by boiling for $10 \mathrm{~min}$ with $2 \% \beta$ mercaptoethanol. The numbers in the center represent molecular weight standards.

strument Division, Kratos, Inc., Westwood, NJ) of autoradiograms of the protein after it had been electrophoresed on reduced polyacrylamide gels in SDS.

Purified HMWK was radiolabeled with ${ }^{125} \mathrm{I}-\mathrm{Na}$ using Iodogen by the method of Fraker and Speck (24) under conditions previously described (17). Purified HMWK (100-250 $\mu \mathrm{g})$ in $0.02 \mathrm{M}$ Tris- $\mathrm{HCl}, 1.0 \mathrm{M} \mathrm{NaCl}$, pH 8.0 was incubated with equal amounts of ${ }^{125} \mathrm{I}-\mathrm{Na}(1 \mathrm{mCi})$ and sodium iodide carrier in a polypropylene tube chilled on ice. The starting ratio of total iodide/HMWK was 2:1. This mixture was transferred to another propylene tube that had been precoated with $4 \mu \mathrm{g}$ of Iodogen and incubated for 30-60 min on ice. The reaction was stopped by the addition of sodium metabisulfite (final concentration, $50 \mu \mathrm{g} / \mathrm{ml}$ ) and free ${ }^{125} \mathrm{I}$ was separated from protein-bound ${ }^{125} \mathrm{I}$ by gel filtration on a $0.8 \times 10 \mathrm{~cm}$ column of Sephadex G-50 equilibrated in $0.02 \mathrm{M}$ Tris-Cl, $1.0 \mathrm{M} \mathrm{NaCl}$, $\mathrm{pH} 8.0$, containing $0.25 \%$ gelatin. The specific radioactivity of the protein varied from 1 to $7 \mu \mathrm{Ci} / \mu \mathrm{g}$ and $>70 \%$ of the molecules of HMWK were iodinated. The radiolabeled protein was $>95 \%$ trichloroacetic acid-precipitable and retained $>95 \%$ of its procoagulant activity as well as its antigenic properties. ${ }^{125} \mathrm{I}$-bovine serum albumin (BSA) was prepared by á similar procedure using lodogen (24).

PK was purified by the method of Scott et al. (25). Protein determinations were performed by the method of Bradford (26) using crystalline BSA as the standard.

Functional and immunochemical assays. HMWK procoagulant activity was measured by a one-stage kaolin activation assay (27) using total kininogen-deficient plasma as substrate. Samples were compared against a daily standard curve from pooled normal human plasma diluted $1 / 10$ to $1 / 1,000$ with $0.01 \mathrm{M}$ Tris $0.15 \mathrm{M} \mathrm{NaCl}, \mathrm{pH} 7.4$. One unit was defined as that amount in $1 \mathrm{ml}$ of pooled normal plasma. HMWK antigen was assayed by electroimmunodiffusion using monospecific antisera to the light-chain of HMWK as described previously (17). Total platelet HMWK was measured by a competitive enzyme-linked immunosorbent assay (ELISA), performed as previously published (17). PK coagulant activity (Fletcher factor) was measured by a modification of the activated partial thromboplastin time using PK-deficient plasma as substrate as previously described (28). $1 \mathrm{U}$ of coagulant activity was defined as the amount present in $1 \mathrm{ml}$ of normal pooled plasma. Radial immunodiffusion (29) using goat antisera monospecific to human PK/kallikrein was used to quantitate PK antigen as previously described (30).

Preparation of washed platelets. Platelet-rich plasma (21) was obtained from citrated human blood and gel filtered on a Sepharose 2B column (31) equilibrated in calcium-free Tyrode's buffer $(0.135 \mathrm{M} \mathrm{NaCl}, 2.7$ $\left.\mathrm{mM} \mathrm{KCl}, 11.9 \mathrm{mM} \mathrm{NaHCO}_{3}, 0.36 \mathrm{mM} \mathrm{NaH}_{2} \mathrm{PO}_{4}, \mathrm{pH} 7.35\right)$ with Hepes $(14.7 \mathrm{mM}), \operatorname{BSA}(1 \mathrm{mg} / \mathrm{ml})$, and dextrose $(3.5 \mathrm{mg} / \mathrm{ml})(32)$. Unless stated otherwise in the text, this buffer, which is called Hepes Tyrode's buffer, also contained $2 \mathrm{mM} \mathrm{Mg}^{++}$. Platelets were counted electronically (Coulter Electronics, Inc., Hialeah, FL). Before and after gel filtration, all platelet preparations were studied for their ability to respond to ADP $(1-5 \mu \mathrm{M})$ when stirred in an aggregometer (Chronolog Corp., Havertown, PA). Fibrinogen (final concentration, $200 \mu \mathrm{g} / \mathrm{ml}$ ) was added to the gel-filtered platelets before the addition of the agonist, ADP. Only platelets that responded to ADP ( $\leq 5 \mu \mathrm{M})$ with both primary and secondary wave platelet aggregation in platelet-rich plasma and $\operatorname{ADP}(\leq 5 \mu \mathrm{M})$ and human fibrinogen $(200 \mu \mathrm{g} / \mathrm{ml})$ after gel filtration were used in the binding studies. In experiments with prostaglandin $\mathrm{E}_{1}\left(\mathrm{PGE}_{1}\right)$-treated platelets, blood was collected into anticoagulant containing $2 \mu \mathrm{M} \mathrm{PGE}_{1}$ and the platelet-rich plasma was gel-filtered in buffer and on Sepharose $2 \mathrm{~B}$ which was equilibrated with $2 \mu \mathrm{M} \mathrm{PGE}_{1}$. After gel filtration, the washed platelets were tested to respond to $5 \mu \mathrm{M}$ ADP in the presence of $200 \mu \mathrm{g} / \mathrm{ml}$ fibrinogen in an aggregometer. If the platelets responded to ADP, an additional treatment with $\mathrm{PGE}_{1}$ (final concentration, $2 \mu \mathrm{M}$ ) was given to the washed platelets before initiating binding studies.

Platelets were also prepared by the centrifugation technique of Mustard et al. (33). Nine parts blood were collected into one part anticoagulant consisting of $73 \mathrm{mM}$ citric acid, $3 \mathrm{mM}$ trisodium citrate containing $2 \%$ dextrose and platelet-rich plasma was obtained (21). After adjusting the $\mathrm{pH}$ of the platelet-rich plasma to 6.5 with citric acid, the platelet-rich plasma was washed twice by centrifugation. The Tyrode's buffer containing $\mathrm{Ca}^{++}(2 \mathrm{mM})$ and $\mathrm{Mg}^{++}(1 \mathrm{mM})$ had both apyrase and heparin $(12.5 \mathrm{U} / \mathrm{ml})$ in the first wash and apyrase alone in the second wash. Apyrase was titered so that the minimal amount necessary to prevent second-wave platelet aggregation with ADP was used. The final washed platelets were resuspended in Hepes Tyrode's buffer (32).

On scanning electron microscopy, washed platelets from both techniques had some pseudopodia. In this manuscript, the term unstimulated platelets refers to platelets which did not receive exogenous agonists.

The HMWK content of washed platelets was studied by the techniques previously reported (17). Briefly, washed platelets were solubilized with $0.5 \%$ Triton $\mathrm{X}-100$ for $30 \mathrm{~min}$ at $23^{\circ} \mathrm{C}$. The platelet lysates were then studied for their HMWK content by a competitive ELISA (17).

Immunofluorescence of washed platelets. Immunofluorescence staining of thrombin-treated or buffered-treated platelets was performed by the technique of Wencel-Drake et al. (34). Briefly, gel-filtered platelets were left untreated or stimulated with thrombin $(0.1 \mathrm{U} / \mathrm{ml})$ in the presence of Gly-Pro-Arg-Pro $(0.4 \mathrm{mM})$ to prevent fibrin formation and platelet aggregation (35). Aliquots of each platelet preparation were fixed with $2 \%$ paraformaldehyde on ice for $1 \mathrm{~h}$. Unreacted aldehyde was blocked with $\mathrm{NH}_{4} \mathrm{Cl}$-Tris-buffered saline, $\mathrm{pH} 7.4$, and the cells were permitted to settle on polylysine-coated glass coverslips. In some cases, the cells were treated with $0.1 \%$ Triton $\mathrm{X}-100$ for 3 min to render them permeable to antibody before staining. The permeable or intact cells were then incubated for 20 min with either specific antibody or preimmune rabbit serum. The cells were rinsed with Tris-buffered saline containing $0.1 \%$ radioimmunoassay grade BSA and stained for $20 \mathrm{~min}$ with a fluoresceinlabeled goat antirabbit IgG (Sigma Chemical Co.). The platelets were viewed at a magnification of 400 with an Olympus $\mathrm{BH}_{2}$ microscope (Olympus Corp., New Hyde Park, NY) equipped with a 100-W mercury lamp for phase contrast and epifluorescence microscopy with a chromatic splitter and 0515 barrier filter and photography using 3M ISO 1000 film. Identical photographic exposure, development, and printing times were used to depict immune and nonimmune (control) immunofluorescence. Antiplatelet glycoprotein antiserum (36) used in the immunofluorescence was the generous gift of Dr. Alan Gewirtz, Temple University, Philadelphia, PA. Antiserum to the platelet activation-dependent granuleexternal membrane (PADGEM) protein $(37,38)$ was the generous gift of Dr. Barbara Furie and Dr. Cindy Berman, New England Medical Center, Boston, MA. The PADGEM protein is a platelet alpha granule membrane protein which only becomes expressed on the external membrane of activated platelets $(37,38)$.

Atomic absorption spectroscopy. Atomic absorption spectroscopy was performed in a Perkin-Elmer Mass Spectrophotometer (Model 4000 AA, Perkin-Elmer, Corp., Norwalk, CT). For determination of magnesium, 
a stock standard solution of $83 \mathrm{mM}$ magnesium was prepared and serial dilutions from 41.6 to $0.58 \mu \mathrm{M}$ were prepared and used as the standard curve. A 285.2-nm wavelength and a $0.7-\mathrm{nm}$ slit width were used. For zinc determination, a stock standard solution of $16.6 \mathrm{mM}$ of zinc was made and serial dilutions from 33 to $0.6 \mu \mathrm{M}$ were prepared. The wavelength was $214 \mathrm{~nm}$ and the slit width was $0.7 \mathrm{~nm}$. For the determination of calcium, a stock solution of $25 \mathrm{mM}$ was prepared in $0.01 \%$ lanthanum chloride and serial dilutions from 200 to $6.25 \mu \mathrm{M}$ were prepared. The wavelength was $423 \mathrm{~nm}$ and the slit width was $0.7 \mathrm{nM}$. For all ion determinations a nitrous oxide-acetylene flame was used. Deionized water was used for a blank setting at $\mathbf{0 . 0 0 0}$. Hepes Tyrode's buffer with or without added magnesium ( $2 \mathrm{mM}$ final concentration) and BSA ( $2 \mathrm{~g} /$ liter) and dextrose $(1 \mathrm{~g} /$ liter $)$ were prepared. The levels of $\mathrm{Zn}^{++}, \mathrm{Mg}^{++}$, and $\mathrm{Ca}^{++}$were determined for both buffers (Hepes Tyrode's without and with magnesium) before and after passage through a $1 \times 5 \mathrm{~cm}$ Chelex 100 column. Before passage through the column, the concentration of $\mathrm{Zn}^{++}$was $3 \mu \mathrm{M} ; \mathrm{Ca}^{++}, 12 \mu \mathrm{M}$; and $\mathrm{Mg}^{++}, 50 \mu \mathrm{M}$-in the absence of added magnesium. After passage through the column, the concentration of each of the divalent cations was $\leq 1 \mu \mathrm{M}$ (the limit of sensitivity of atomic absorption spectroscopy).

Binding experiments. In all binding experiments platelets were at a final concentration of $2 \times 10^{8} / \mathrm{ml}$. In a typical binding experiment 200 $300 \mu \mathrm{l}$ of gel-filtered platelets in Hepes Tyrode's buffer, $\mathrm{pH} 7.35$ were incubated at $37^{\circ} \mathrm{C}$ without stirring in a $1.5 \mathrm{ml}$ polypropylene centrifuge tube (Sarstedt, Inc., Princeton, NJ) with radiolabeled HMWK and additions of a total volume of 250-350 $\mu$ l. After incubation of appropriately expanded volumes, $50-\mu 1$ aliquots were removed (in triplicate) for each experimental point and centrifuged at $9,650 \mathrm{~g}$ at $23^{\circ} \mathrm{C}$ in a microfuge (Model B; Beckman Instruments, Inc., Fullerton, CA) through a 200- $\mu$ l mixture of silicon oils (one part Apiezion/nine parts $N$-butyl-phthalate) in polypropylene microsediment tubes with narrow bore extended tips (Sarstedt, Inc.) for $2 \mathrm{~min}$ at room temperature. After the supernatant was carefully removed, the tips containing the pellet were amputated and counted in a Rack gamma counter (LKB Instruments, Inc., Gaithersburg, MD).

Unless otherwise stated, all binding assays were performed on washed platelets with additions that were incubated for 10-15 min before centrifugation through oil.

Measurement of trapped aqueous volume and nonspecific binding. Platelets were incubated with ${ }^{125} \mathrm{I}$-labeled HMWK BSA for $50 \mathrm{~min}$ at $37^{\circ} \mathrm{C}$ and centrifuged over a mixture of silicone oils as described above. The fraction of the radiolabeled BSA that sedimented was assumed to correspond to the fraction of aqueous volume that sedimented, since the buffer contained $1 \mathrm{mg} / \mathrm{ml}$ BSA. The fraction of the radiolabeled BSA that appeared in the pellet was $<0.2 \%$ of the total volume in a typical binding experiment.

Nonspecific binding was determined in simultaneously performed experiments with identical amounts of ${ }^{125} \mathrm{I}$-HMWK and additions in the presence of 50-fold or 100-fold molar excess of unlabeled HMWK. If a 50 -fold excess of unlabeled HMWK was used, nonspecific binding was $\leq 0.5 \%$ of the radioactivity added. Nonspecific binding was $\leq 0.4 \%$ of added radioactivity with a 100 -fold molar excess of unlabeled HMWK.

Characterization of platelet-bound ${ }^{125} I-H M W K$. The form of ${ }^{125} \mathrm{I}-$ HMWK bound to platelets was assessed by solubilizing platelet pellets with bound ${ }^{125} \mathrm{I}-\mathrm{HMWK}$ in $4 \%$ SDS containing $0.5 \mathrm{mM}$ leupeptin. After reduction of the solubilized platelet pellet and its supernatant with $2 \%$ $\beta$-mercaptoethanol, the samples were applied to an $8 \%$ polyacrylamide gel in SDS for electrophoresis. The structure of platelet-bound ${ }^{125} \mathrm{I}-$ HMWK was determined by performing autoradiography on the dried gel. Leupeptin was added to the $4 \%$ SDS to prevent proteolysis of the platelet-bound ${ }^{125} \mathrm{I}-\mathrm{HMWK}$ by platelet calpains during the solubilization (18).

Expression and calculations of binding experiments. Calculation of bound HMWK was based on the specific activities of the radiolabeled ligand, and results were expressed as nanograms of HMWK bound per $10^{8}$ platelets. In concentration dependence experiments, total binding was the amount of ${ }^{125}$ I-HMWK bound in the absence of a 50 -fold molar excess of unlabeled ligand, while nonspecific binding was the amount of
${ }^{125}$ I-HMWK bound in the presence of the molar excess of unlabeled ligand. "Specific" binding was obtained by subtracting the nonspecific binding from the total binding.

Competitive binding of ${ }^{125} \mathrm{I}-\mathrm{HMWK}$ and unlabeled HMWK to platelets were analyzed by a four-parameter logistic function, $Y=d+(a$ $-d) /(1+X / c)^{b}$, where $X$ and $Y$ are the concentration of the unlabeled HMWK and radiolabeled HMWK bound, respectively; $c$ is the $50 \%$ inhibitory concentration by unlabeled HMWK; $b$ is the steepness factor; and $a$ and $d$ are the extrapolated upper and lower limits for the observed value of $Y$, when $X$ is 0 or infinite, respectively (39), using a computer program developed by Canellas and Karu (40). Estimation of the affinity constant of the binding was performed by the technique of Muller (41) using the formula $K_{\mathrm{a}}=8 / 3\left(\left[I_{t}\right]-\left[T_{t}\right]\right)$ where $\left[I_{t}\right]$ equals the molar concentration of the $50 \%$ inhibitory concentration of unlabeled HMWK and $\left[T_{t}\right]$ is the molar concentration of ${ }^{125} \mathrm{I}$-HMWK tracer. ${ }^{125} \mathrm{I}$-HMWK platelet binding was also analyzed by the graphical methods of Scatchard (42), and Klotz (43) as well as the computer programs of Munson and Rodbard (44) and Brass and Shattil (45) using an Apple Ile computer (Apple Computer Corp., Cupertino, CA). Experimental results at each concentration of the total dose of ligand (both labeled and unlabeled) and bound radioligand were fed into a preanalysis program (44). After calculating the amount of free ligand the data were also fit by the program developed by Brass and Shattil (45). When using this latter program, evaluable results were those with a calculated error of $<0.02 \%$ and a generated curve that intersected all the data points. A group paired $t$ test was used to determine if binding data from various experiments were different.

\section{Results}

Binding of ${ }^{125}$ I-labeled HMWK to unstimulated and thrombinactivated platelets. The requirement for platelet activation to demonstrate HMWK binding to platelets was ascertained by measuring the amount of ${ }^{125} \mathrm{I}$-HMWK-platelet binding to platelets activated by variable concentrations of thrombin (Fig. 2). In the absence of thrombin, $4.6 \mathrm{ng}{ }^{125} \mathrm{I}-\mathrm{HMWK} / 10^{8}$ platelets were bound. This binding to unstimulated platelets was specific because in the presence of a 50 -fold molar excess of unlabeled HMWK, the nonspecific binding was $<30 \%$ of the total binding.

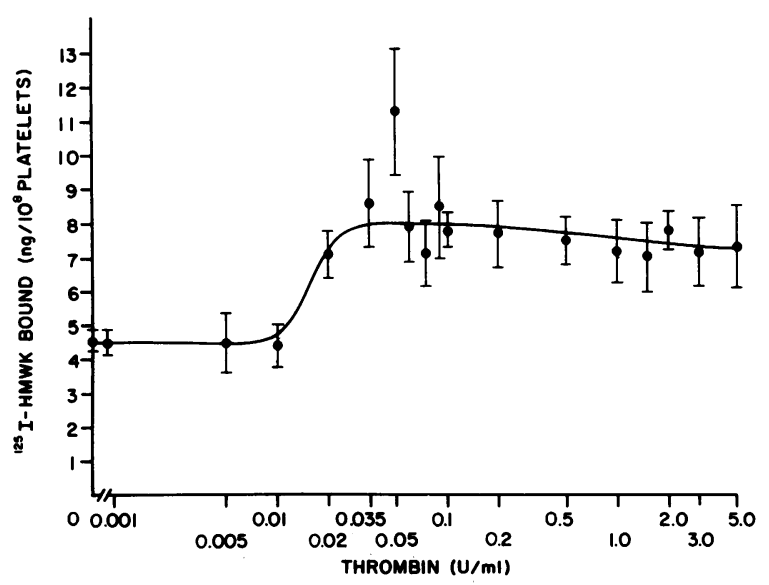

Figure 2. The effect of thrombin concentration on ${ }^{125} \mathrm{I}-\mathrm{HMWK}$ binding to platelets. Gel-filtered platelets $\left(2.2 \times 10^{8} / \mathrm{ml}\right)$ in Hepes Tyrode's buffer, pH 7.35 , were incubated at $37^{\circ} \mathrm{C}$ with ${ }^{125} \mathrm{I}$-labeled HMWK (1 $\mu \mathrm{g} / \mathrm{ml})$ in the presence of $\mathrm{Zn}^{++}(50 \mu \mathrm{M})$ and thrombin at the concentrations indicated. After 10 min incubation, the amount of ${ }^{125} \mathrm{I}$ HMWK bound to the platelets was determined as indicated in Methods. The results presented are the mean \pm SEM of seven separate experiments and the plotted data represent total binding. 
After thrombin activation of platelets $(0.001-0.01 \mathrm{U} / \mathrm{ml})$, there was no significant increase $(P>0.05)$ in the amount of ${ }^{125} \mathrm{I}$ HMWK that bound to platelets over unstimulated platelets when platelets were incubated with radioligand for $10 \mathrm{~min}$. However, at concentrations of thrombin $\geq 0.02 \mathrm{U} / \mathrm{ml}$, there was a significant increase $(P<0.01)$ in the amount of ${ }^{125} \mathrm{I}-\mathrm{HMWK}$ bound to that seen with unstimulated platelets and that at the lower doses of thrombin. These results indicated that ${ }^{125} \mathrm{I}-\mathrm{HMWK}$ substantially bound to both unstimulated and activated platelets.

The ability of ${ }^{125} \mathrm{I}-\mathrm{HMWK}$ to bind to platelets in the absence of exogenous activation was further studied by three independent approaches. In the first approach, binding of ${ }^{125} \mathrm{I}-\mathrm{HMWK}$ to platelets prepared by gel filtration was compared with binding to platelets prepared by the centrifugation technique of Mustard et al. (33). Binding of ${ }^{125} \mathrm{I}-\mathrm{HMWK}$ to unstimulated platelets washed by either technique increased over time with a similar kinetic pattern (data not shown). At $10 \mathrm{~min}, 3.0 \mathrm{ng}$ and $2.9 \mathrm{ng}$ ${ }^{125} \mathrm{I}$-HMWK were bound per $10^{8}$ platelets for gel-filtered platelets and centrifugation-washed platelets, respectively. The amount of ${ }^{125}$ I-HMWK bound to platelets washed by either technique was not significantly different $(P>0.25)$ at all time points (1$50 \mathrm{~min}$ ). This study indicated that the ability of ${ }^{125} \mathrm{I}-\mathrm{HMWK}$ to bind to unstimulated platelets was not a function of the technique used to prepare the platelets.

As a second approach to determine that ${ }^{125} \mathrm{I}-\mathrm{HMWK}$ was binding to unstimulated platelets, a series of experiments was performed comparing binding of ${ }^{125} \mathrm{I}-\mathrm{HMWK}$ to gel-filtered platelets prepared in the absence or presence of $2 \mu \mathrm{M} \mathrm{PGE}_{1}$. In these experiments, ${ }^{125} \mathrm{I}$-HMWK bound equally to the two preparations of gel-filtered platelets. At $10 \mathrm{~min}, 3.7 \mathrm{ng}{ }^{125} \mathrm{I}-\mathrm{HMWK} /$ $10^{8}$ platelets \pm 1.1 (mean \pm SD) bound to gel-filtered platelets and $3.4 \mathrm{ng}{ }^{125} \mathrm{I}-\mathrm{HMWK} / 10^{8}$ platelets \pm 0.6 bound to $\mathrm{PGE}_{1}$-treated gel filtered platelets. These results were not demonstrated to be significantly different $(P>0.15)$.

We performed immunofluorescence studies on unstimulated and activated platelets using antiserum directed to the PADGEM antigen $(37,38)$ to determine if the gel-filtered platelets used in the binding studies were activated. When we used Triton X-100 permeabilized platelets, both an anti-platelet glycoprotein antibody and the PADGEM antibody produced positive immunofluorescence that diffusely stained the platelets. When gelfiltered platelets were activated with $0.1 \mathrm{U} / \mathrm{ml}$ thrombin, a rim pattern of immunofluorescence was seen with the PADGEM antibody. However, when gel-filtered platelets were fixed after washing without permeabilization with Triton X-100 or without treatment with thrombin, no immunofluorescent staining was detected when the platelets were reacted with the PADGEM antibody. This study indicated that the gel-filtered platelets used in the present studies were unstimulated. These combined investigations indicated that the washed platelets used in these binding studies were unstimulated platelets.

Effect of divalent cations on ${ }^{125}$ I-HMWK binding to unstimulated platelets. In order to establish the optimal conditions for ${ }^{125} \mathrm{I}-\mathrm{HMWK}$-platelet binding, studies were carried out to determine the divalent cation requirements for ${ }^{125} \mathrm{I}-\mathrm{HMWK}$ binding to unstimulated platelets (Fig. 3). Binding of ${ }^{125} \mathrm{I}-\mathrm{HMWK}$ to platelets increased with time at all concentrations of $\mathrm{Zn}^{++}$and was greatest at any time point with a concentration of $50 \mu \mathrm{M}$ added $\mathrm{Zn}^{++}$. However, binding of ${ }^{125} \mathrm{I}-\mathrm{HMWK}$ to platelets in

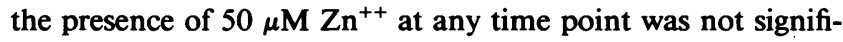
cantly greater than that seen at 25 or $100 \mu \mathrm{M}$ added zinc $(P$ $\geq 0.10$ and $P \geq 0.05$, respectively). The amount of ${ }^{125} \mathrm{I}$-HMWK

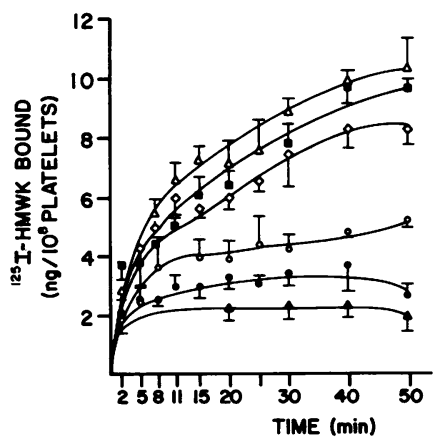

Figure 3. Effect of $\mathrm{Zn}^{++}$ concentration on ${ }^{125} \mathrm{I}$ HMWK binding to unstimulated platelets. Time course experiments: Gel-filtered platelets $\left(2.2 \times 10^{8} /\right.$ $\mathrm{ml}$ ) in Hepes Tyrode's buffer, $\mathrm{pH} 7.35$, were incubated at $37^{\circ} \mathrm{C}$ with ${ }^{125} \mathrm{I}$-labeled HMWK $(1 \mu \mathrm{g} / \mathrm{ml})$ for variable time periods in the presence of varying concentration of $\mathrm{Zn}^{++}: 0 \mu \mathrm{M}$,

$25 \mu \mathrm{M}, \varpi ; 50 \mu \mathrm{M}, \Delta ; 100 \mu \mathrm{M}, \diamond ;$ and $200 \mu \mathrm{M}, \diamond$. Nonspecific binding (NS) was measured in the presence of a 50 -fold molar excess of unla-

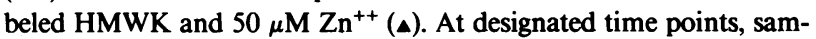
ples were removed and ${ }^{125} \mathrm{I}$-HMWK-platelet binding was determined as indicated in Methods. The plotted data are the mean \pm SEM of six experiments and represent total binding.

bound with $200 \mu \mathrm{M}$ added $\mathrm{ZnCl}_{2}$ was significantly less ( $P$ $<0.001)$ than the amount bound with any of the above concentrations of zinc. The amount of ${ }^{125} \mathrm{I}-\mathrm{HMWK}$ bound in the presence of $50 \mu \mathrm{M} \mathrm{Zn}^{++}$and a 50 -fold molar excess of unlabeled HMWK was not significantly different from the amount bound with no added $\mathrm{ZnCl}_{2}(P>0.05)$. Passage of the buffer through Chelex 100 resin did not decrease the level of binding seen when no zinc was added. These findings indicated that there is an optimal concentration of $\mathrm{Zn}^{++}(25-100 \mu \mathrm{M})$ which results in maximal binding of ${ }^{125} \mathrm{I}-\mathrm{HMWK}$ to unstimulated platelets. These concentrations of zinc correspond to the physiological levels of zinc in plasma (46).

We performed further studies to determine the contribution of the divalent cations, calcium and magnesium, on ${ }^{125} \mathrm{I}-\mathrm{HMWK}$ binding to unstimulated platelets. Calcium ion alone could not support ${ }^{125} \mathrm{I}$-HMWK binding to platelets. Using platelets washed in the presence of $2 \mathrm{mM} \mathrm{Mg}{ }^{++}, \mathrm{Ca}^{++}$in a concentration from 0.5 to $7.0 \mathrm{mM}$ did not contribute to any statistically significantly greater ${ }^{125} \mathrm{I}$-HMWK platelet binding to unstimulated platelets in the presence of $50 \mu \mathrm{M} \mathrm{Zn}^{++}$than zinc alone $(P \geq 0.1)$. Additional studies were performed to determine whether magnesium ion contributed to ${ }^{125} \mathrm{I}-\mathrm{HMWK}$ platelet binding. When we used platelets washed in the absence of magnesium, the level of ${ }^{125} \mathrm{I}-\mathrm{HMWK}$ platelet binding in the presence of $2 \mathrm{mM} \mathrm{Mg}^{++}$ alone was not significantly different than that found in the presence of $50 \mu \mathrm{M}$ zinc and a 50 -fold molar excess of unlabeled HMWK $(P \geq 0.30)$. Moreover, binding of ${ }^{125} \mathrm{I}$-HMWK to un-

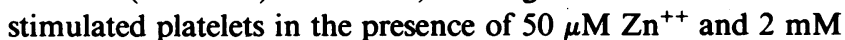
$\mathrm{Mg}^{++}$was not significantly greater than the binding seen in the presence of zinc alone $(P \geq 0.30)$. However, binding of the radiolabeled ligand in the presence of zinc was significantly greater than any binding in the absence of zinc $(P<0.005)$. These combined studies suggest that neither calcium nor magnesium contribute to the ability of ${ }^{125} \mathrm{I}-\mathrm{HMWK}$ to bind to unstimulated platelets.

The combined effect of $\mathrm{Zn}^{++}, \mathrm{Ca}^{++}$, and $\mathrm{Mg}^{++}$on ${ }^{125} \mathrm{I}-$ HMWK platelet binding to unstimulated platelets was studied further (Fig. 4). In Fig. $4 A$, platelets were prepared in the presence of $2 \mathrm{mM} \mathrm{Mg}^{++}$and ${ }^{125} \mathrm{I}-\mathrm{HMWK}$ platelet binding was performed in the presence of $2 \mathrm{mM} \mathrm{Ca}^{++}$. In these experiments, specific binding of ${ }^{125} \mathrm{I}-\mathrm{HMWK}$ to unstimulated platelets only occurred in the presence of zinc ion. When zinc was excluded from the 

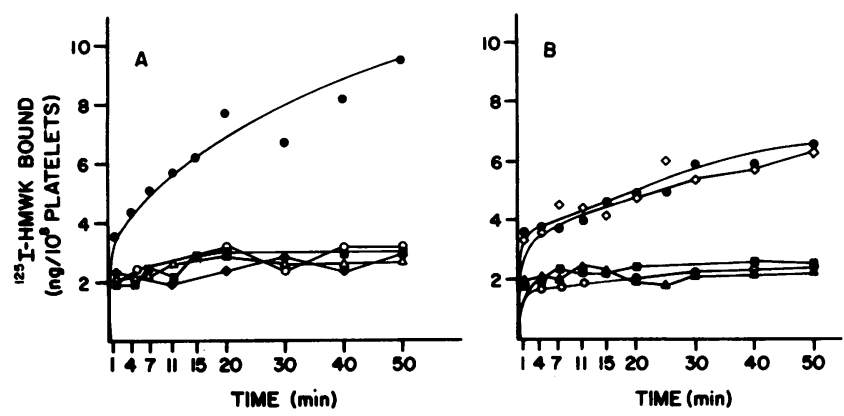

Figure 4. Effect of chelators of divalent cations on HMWK binding to unstimulated platelets. Gel-filtered platelets $\left(2.2 \times 10^{8} / \mathrm{ml}\right)$ in Hepes Tyrode's buffer were prepared in the presence $(A)$ or absence $(B)$ of 2 $\mathrm{mM} \mathrm{Mg}{ }^{++}$and incubated at $37^{\circ} \mathrm{C}$ for $2-50$ min with ${ }^{125} \mathrm{I}$-labeled HMWK $(1 \mu \mathrm{g} / \mathrm{ml})$ and various combinations of divalent cations. In each experiment where an addition was made the concentration of $\mathrm{Zn}^{++}$was $50 \mu \mathrm{M} ; \mathrm{Ca}^{++}, 2 \mathrm{mM}$; and $\mathrm{Mg}^{++}, 2 \mathrm{mM}$. At the designated time points, ${ }^{125} \mathrm{I}$-HMWK-platelet binding was determined as indicated in Methods. In $\mathrm{A}:-\bullet-, \mathrm{Zn}^{++}, \mathrm{Ca}^{++}$and $\mathrm{Mg}^{++}$(total); - - , $\mathrm{Zn}^{++}, \mathrm{Ca}^{++}, \mathrm{Mg}^{++}$plus EDTA (10 mM); $-\Delta-, \mathrm{Zn}^{++}, \mathrm{Ca}^{++}, \mathrm{Mg}^{++}$ plus EGTA $(10 \mathrm{mM}) ;-\downarrow, \mathrm{Ca}^{++}, \mathrm{Mg}^{++}$alone but no $\mathrm{Zn}^{++}$; and $-0-, \mathrm{Zn}^{++}, \mathrm{Ca}^{++}, \mathrm{Mg}^{++}$in the presence of $50 \mu \mathrm{g} / \mathrm{ml}$ unlabeled HMWK (nonspecific). The data plotted are the mean of three experiments with platelets washed in the presence of $\mathrm{Mg}^{++}$and represent total binding. In $\mathrm{B},-\bullet-, \mathrm{Zn}^{++}, \mathrm{Ca}^{++}$and $\mathrm{Mg}^{++}$(total); $-\diamond-, \mathrm{Zn}^{++}$ alone; -,$- \mathrm{Zn}^{++}$plus EDTA (10 mM); - $-, \mathrm{Ca}^{++}, \mathrm{Mg}^{++}$alone but no $\mathrm{Zn}^{++}$; and $-\mathrm{O}-, \mathrm{Zn}^{++}, \mathrm{Ca}^{++}, \mathrm{Mg}^{++}$in the presence of 50 $\mu \mathrm{g} / \mathrm{ml}$ unlabeled HMWK (nonspecific). The plotted data are the mean of six experiments with platelets washed in the absence of $\mathrm{Mg}^{++}$and represent total binding.

divalent cation mixture, or EDTA $(10 \mathrm{mM})$ or EGTA $(10 \mathrm{mM})$ was included in the reaction mixture, the level of binding was not any different than that seen when binding was performed in the presence of a 50 -fold molar excess of unlabeled HMWK. In Fig. $4 \mathrm{~B}$, platelets were prepared in the absence of $\mathrm{Mg}^{++}$. These washed platelets with no added $\mathrm{Mg}^{++}$aggregated to $5 \mu \mathrm{M}$ ADP in the presence of $200 \mu \mathrm{g} / \mathrm{ml}$ human fibrinogen. In these experiments, specific ${ }^{125} \mathrm{I}-\mathrm{HMWK}$ binding to unstimulated platelets again only occurred when $\mathrm{Zn}^{++}$was present. Moreover, the level of ${ }^{125} \mathrm{I}$-HMWK-platelet binding with zinc alone was not significantly different than that seen with $\mathrm{Zn}^{++}$in the presence of added calcium and magnesium ions $(P \geq 0.50)$. In the absence of zinc or in the presence of $10 \mathrm{mM}$ EDTA, the level of ${ }^{125} \mathrm{I}$-HMWK-platelet binding was not any different than that seen with zinc in the presence of a 50-fold molar excess of unlabeled HMWK. These combined studies indicated that $\mathrm{Zn}^{++}$ is the sole divalent cation requirement for ${ }^{125} \mathrm{I}-\mathrm{HMWK}$ binding to unstimulated platelets.

Specificity of ${ }^{125} \mathrm{I}-\mathrm{HM}$ WK platelet binding to unstimulated platelets. Three approaches were utilized to establish that binding of ${ }^{125} \mathrm{I}$-HMWK to the unstimulated platelet was specific. First, it was determined that the observed interaction of ${ }^{125} \mathrm{I}-\mathrm{HMWK}$ with platelets was not due to radioiodination of the HMWK. Gel filtered platelets were incubated in the presence of mixtures of ${ }^{125}$ I-HMWK and unlabeled HMWK at a constant total concentration of HMWK. As the proportion of radiolabeled HMWK to unlabeled HMWK increased, a linear relationship was observed in the percentage of ${ }^{125} \mathrm{I}-\mathrm{HMWK}$ in the mixtures and the amount bound (Fig. 5). The linear correlation coefficient of $r$ $>0.98$ indicated that the labeled and nonlabeled HMWK interacted with the platelet with the same apparent affinity.

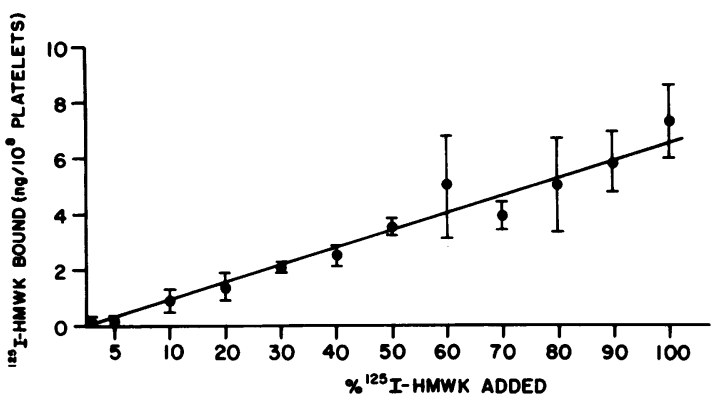

Figure 5. Relative binding of ${ }^{125} \mathrm{I}$-labeled HMWK and unlabeled HMWK to unstimulated platelets. Gel-filtered platelets $\left(2.2 \times 10^{8} / \mathrm{ml}\right)$ in Hepes Tyrode's buffer, $\mathrm{pH} 7.35$, were incubated for $10 \mathrm{~min}$ at $37^{\circ} \mathrm{C}$ with $\mathrm{Zn}^{++}(50 \mu \mathrm{M})$ and various proportions of ${ }^{125}$ I-labeled and unlabeled HMWK, keeping the total concentration of HMWK constant at $1 \mu \mathrm{g} / \mathrm{ml}$. Binding was determined as detailed in Methods and binding of ${ }^{125}$ I-labeled HMWK was plotted as a function of the fraction of the total made up of added ${ }^{125} \mathrm{I}-\mathrm{HMWK}$. The plotted data are mean \pm SEM of three experiments.

Since $<2 \%$ of the added ${ }^{125}$ I-HMWK was bound by the platelets, we attempted to verify that the observed binding was not limited to a small population of the added ${ }^{125}$ I-ligand. A constant amount of ${ }^{125} \mathrm{I}-\mathrm{HMWK}(1 \mathrm{\mu g} / \mathrm{ml})$ was added to platelets in the absence or presence of a 50-fold molar excess of unlabeled HMWK. After $50 \mathrm{~min}$ at $37^{\circ} \mathrm{C}$, the unbound fraction of the ${ }^{125}$ I-HMWK was transferred to a second platelet suspension and incubated for $50 \mathrm{~min}$. The second unbound fraction was then transferred a third time. No decrease in the percent of the ligand bound to platelets was observed from the first to third transfer. Therefore, the observed specific binding of ${ }^{125}$ I-HMWK to unstimulated platelets did not appear to be limited to a small subpopulation of radiolabeled HMWK molecules. Platelet-bound ${ }^{125}$ I-HMWK from solubilized platelets on autoradiograms of reduced polyacrylamide gels in SDS was identical to the added ${ }^{125}$ I-HMWK ligand.

As a second approach to validate specificity of ${ }^{125}$ I-HMWKplatelet binding, we assessed the capacity of unlabeled HMWK, related contact phase proteins, and unrelated coagulation proteins to inhibit the platelet interaction with ${ }^{125}$ I-HMWK. As shown in Table I, unlabeled HMWK inhibited the binding of the radiolabeled ligand by $>79 \%$, which confirmed previous estimates of nonspecific binding of $<30 \%$ of total binding. In 10 experiments using at least five different preparations of labeled ligand, the level of nonspecific binding was $17 \pm 3 \%$ (mean \pm SEM). Binding of ${ }^{125}$ I-HMWK was not inhibited by a $25-100$-fold molar excess of PK, Factor XI, Factor XII, Factor V, fibronectin, or fibrinogen regardless of whether the competitor and the ${ }^{125} \mathrm{I}$ HMWK incubated 10 or 50 min after simultaneous introduction to the platelets.

A third approach to assess the specificity of ${ }^{125}$ I-HMWK binding to inactivated platelets was to examine the effect of increasing concentrations of unlabeled HMWK on the binding of ${ }^{125} \mathrm{I}$-HMWK when the dose $(7.45 \pm 0.29 \mathrm{nM})$ of the radioligand was held constant (Fig. 6). Unlabeled HMWK competitively inhibited the binding of radiolabeled HMWK. The mean \pm SEM concentration of unlabeled HMWK required for 50\% competition inhibition was $0.71 \pm 0.35 \mu \mathrm{g} / \mathrm{ml}(6.06 \mathrm{nM} \pm 2.9)$, which gave a calculated apparent dissociation constant $\left(K_{d}\right)$ of $1.57 \pm 0.1$ $\mathrm{nM}(41)$. This value was similar to the calculated $K_{\mathrm{d}}(0.52 \mathrm{nM})$ determined from the mean of each point in all experiments used 
Table I. Specificity of ${ }^{125}$ I-HMWK Binding

to Unstimulated Platelets*

\begin{tabular}{lcc}
\hline Protein competitort & $\begin{array}{l}\text { Amount of }{ }^{125} \text { I-HMWK } \\
\text { bound p1§ }\end{array}$ & $\begin{array}{l}\text { HMWK bound as a } \\
\text { percent of control }\end{array}$ \\
\hline None & 11.4 & 100 \\
Unlabeled HMWK (50) & 2.45 & 21 \\
Prekallikrein (100) & 10.69 & 94 \\
Factor XI (25) & 8.58 & 75 \\
Factor XII (100) & 7.75 & 68 \\
Factor V (50) & 15.2 & 133 \\
Fibronectin (50) & 9.74 & 85 \\
Fibrinogen (50) & 8.95 & 79 \\
\hline
\end{tabular}

* ${ }^{125}$ I-labeled HMWK $(1 \mu \mathrm{g} / \mathrm{ml})$ was incubated for $50 \mathrm{~min}$ at $37^{\circ} \mathrm{C}$ with gel-filtered platelets $\left(2 \times 10^{8} / \mathrm{ml}\right)$ in Hepes Tyrode's buffer in the presence of $\mathrm{Zn}^{++}(50 \mu \mathrm{M})$ and $\mathrm{Ca}^{++}(2 \mathrm{mM})$ and various proteins. $\ddagger$ Each competitor was added in the molar excess (which is given by the value in parenthesis) to the final concentration of the ${ }^{125}$ I-HMWK. $\S$ Values presented are the means of 2-3 experiments with different platelet donors.

together to determine a competition inhibition curve and to calculate the midpoint of this curve by a four-parameter logistic function (40) (Fig. 6). These values were in reasonable agreement with a value of $1.34 \pm 0.07 \mathrm{nM}$ determined by computer fit of a high affinity site using a one-site model $(44,45)$. When a twosite model was used, a high affinity binding site was characterized as having an apparent $K_{\mathrm{d}}$ of $0.70 \pm 0.15 \mathrm{nM}$.

Reversibility of ${ }^{125} I-H M W K$ binding to unstimulated platelets. To study the reversibility of binding, we incubated gel-filtered platelets with ${ }^{125} \mathrm{I}-\mathrm{HMWK}$, and after $10 \mathrm{~min}$ and $20 \mathrm{~min}$, added a 50-fold molar excess of unlabeled HMWK. After the addition of the unlabeled ligand, rapid dissociation of bound ligand was observed (Fig. 7). When the unlabeled HMWK was added after $10 \mathrm{~min}$ of incubation, $89 \%$ of the bound radioligand was displaced within $1 \mathrm{~min}$; when unlabeled HMWK was added after $20 \mathrm{~min}$ of incubation, $79 \%$ of the bound radioligand was displaced within $1 \mathrm{~min}$. No further reversal of binding was observed

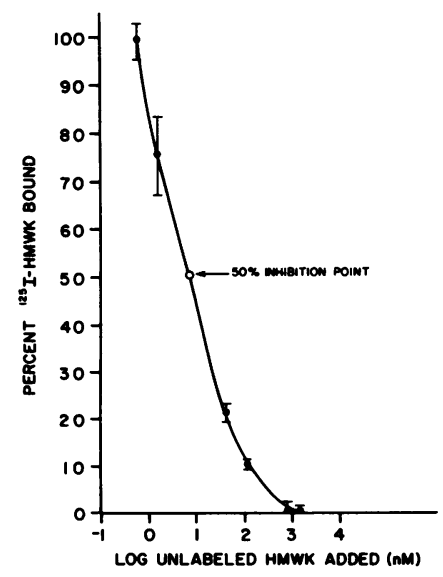

Figure 6. Comparison of the ability of nonlabeled HMWK to competitively inhibit ${ }^{125}$ IHMWK binding to platelets. ${ }^{125} \mathrm{I}$-HMWK $(0.89 \mu \mathrm{g} / \mathrm{ml}[7.45$ $\mathrm{nM}]$ ) were incubated with gelfiltered platelets $\left(2.2 \times 10^{8} / \mathrm{ml}\right)$ in Hepes Tyrode's buffer for 10 $\min$ at $37^{\circ} \mathrm{C}$ in the absence or presence of the indicated concentration of unlabeled HMWK. In the presented figure, the data were fit to a competition inhibition curve generated by a computer program using a four-parameter logistic function (ref. 40) which calcu-

lates the values on the ordinate into relative values between 0 and $100 \%$. The figure presented is the mean \pm SEM of the points derived from three experiments where the concentration of the added ${ }^{125} \mathrm{I}$ HMWK was similar.

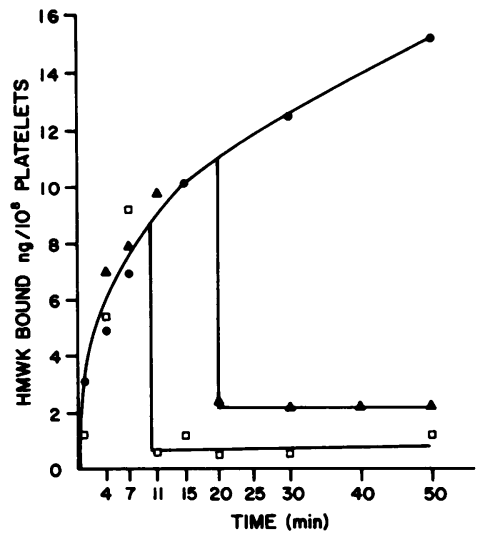

Figure 7. Reversibility of HMWK binding to unactivated platelets. Gel-filtered platelets $\left(2.2 \times 10^{8} / \mathrm{ml}\right)$ in Hepes Tyrode's buffer were incubated for $50 \mathrm{~min}$ at $37^{\circ} \mathrm{C}$ in the presence of $\mathrm{Zn}^{++}(50 \mu \mathrm{M}), \mathrm{Ca}^{++}(2$ $\mathrm{mM})$, and ${ }^{125} \mathrm{I}$-labeled HMWK $(1 \mu \mathrm{g} / \mathrm{ml})$. At 10 $\min (-\square-)$ and $20 \mathrm{~min}$ $(-\Delta-)$ a 50 -fold molar excess of unlabeled HMWK was added. The binding was determined at the indicated time points as detailed in

Methods. The plotted data are one experiment of three and represent total binding in the presence of no added unlabeled ligand $(-\bullet-)$ or with the previously indicated additions.

when the incubations with the unlabeled HMWK were extended to $50 \mathrm{~min}$. When a 50 -fold molar excess of unlabeled HMWK was added after a 50 -min incubation, only $15 \%$ of the radiolabeled ligand was displaced (data not shown).

Two types of experiments were performed to determine that the association of ${ }^{125} \mathrm{I}-\mathrm{HMWK}$ with unstimulated platelets was one of binding and not incorporation or ingestion. Firstly, reversibility binding experiments were performed at 37 and $4^{\circ} \mathrm{C}$. At both temperatures, the extent of association of the radiolabeled ligand to platelets was the same. When a 50-fold molar excess of unlabeled HMWK was introduced to platelets that were incubated with ${ }^{125} \mathrm{I}-\mathrm{HMWK}$ for $20 \mathrm{~min}$ at 37 and $4^{\circ} \mathrm{C}$ in simultaneous but separate experiments, the amount of the radioligand that dissociated from the platelets was $80 \%$ for both incubations. Secondly, studies were performed to determine whether total kininogen-deficient platelets (17) ingested plasma HMWK. Total kininogen-deficient platelets were washed and an aliquot of the washed platelets was incubated in normal plasma $(88 \mu \mathrm{g} / \mathrm{ml} \mathrm{HMWK})$ for $1.5 \mathrm{~h}$ at $37^{\circ} \mathrm{C}$. After the incubation, the normal plasma-treated total kininogen-deficient platelets were rewashed. Both samples of the washed total kininogen deficient platelets were then studied for their total HMWK content. After incubation in normal plasma, the total kininogen-deficient platelets had a HMWK content of $<3.4 \mathrm{ng} /$ $10^{8}$ platelets, a value below the lower limit of the assay and identical to the washed total kininogen-deficient platelets before incubation in normal plasma. These combined studies indicated that the association of HMWK with platelets was one of binding and not incorporation or ingestion.

Saturability of ${ }^{125}$ I-HMWK binding to unstimulated platelets. Since ${ }^{125} \mathrm{I}$-HMWK binding to nonactivated platelets appeared to reach equilibrium at 10 to $20 \mathrm{~min}$, the number and affinity of HMWK binding sites on unstimulated platelets were determined as a function of HMWK concentration. Increasing concentrations of ${ }^{125} \mathrm{I}-\mathrm{HMWK}$ were added to platelets in the presence of $\mathrm{Zn}^{++}(50 \mu \mathrm{M})$ and $\mathrm{Ca}^{++}(2 \mathrm{mM})$ and in the presence or absence of a 50-fold molar excess of unlabeled ligand. Fig. 8 is one representative experiment of six. As the concentration of added ${ }^{125} \mathrm{I}-\mathrm{HMWK}$ increased, the level of binding increased. At lower concentrations of added ${ }^{125} \mathrm{I}-\mathrm{HMWK}(<1 \mu \mathrm{g} / \mathrm{ml}$ added) nonspecific binding was $<20 \%$ of the total binding. At concentrations of added ${ }^{125} \mathrm{I}-\mathrm{HMWK}>1 \mu \mathrm{g} / \mathrm{ml}(8.3 \mathrm{nM})$, the percent of non- 


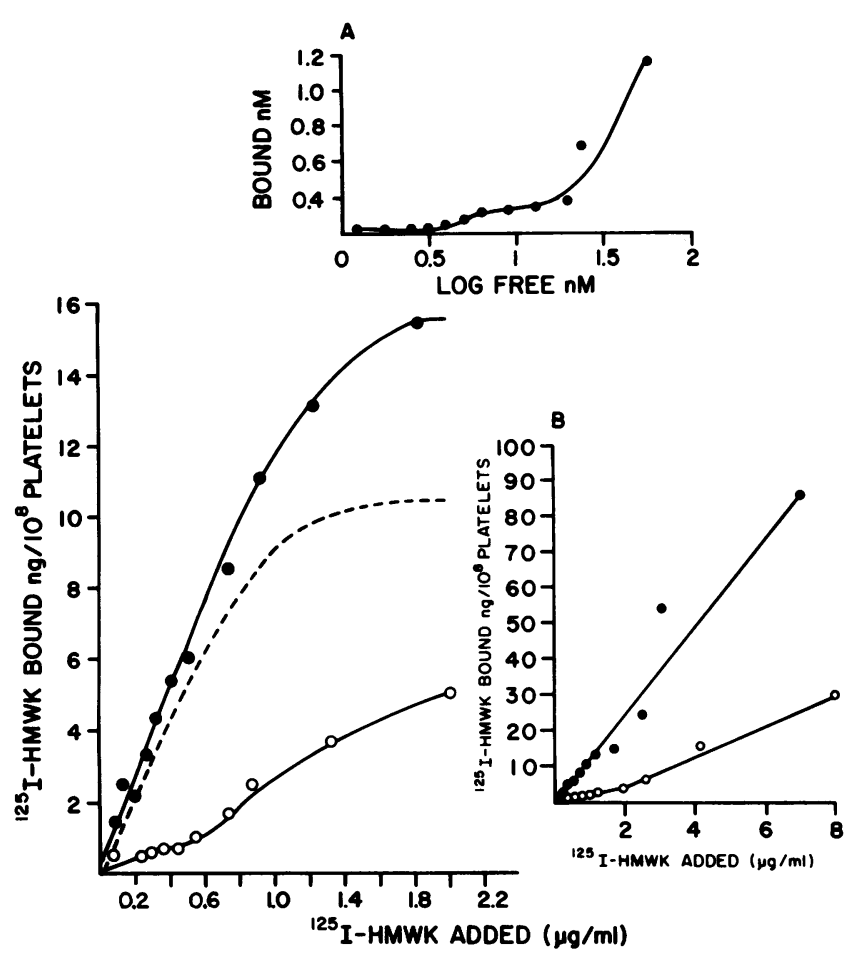

Figure 8. Concentration-dependent binding of ${ }^{125} \mathrm{I}-\mathrm{HMWK}$ to platelets. Platelets at a concentration of $2.2 \times 10^{8} / \mathrm{ml}$ in Hepes Tyrode's buffer were incubated with increasing concentrations of ${ }^{125} \mathrm{I}-\mathrm{HMWK}$ in the presence of $\mathrm{Zn}^{++}(50 \mu \mathrm{M})$ and $\mathrm{Ca}^{++}(2 \mathrm{mM})$ at $37^{\circ} \mathrm{C}$ for 15 min. ${ }^{125} \mathrm{I}$-HMWK-platelet binding was determined as indicated in Methods. Total binding ( $-\bullet-)$ and nonspecific binding (- - ) were directly determined and specific binding (- - - ) was calculated by subtracting nonspecific binding from total binding. Inset $\boldsymbol{A}$ represents a plot of bound ${ }^{125} \mathrm{I}-\mathrm{HMWK}$ (nM) on the ordinate vs. log free (nM) HMWK on the abscissa. The line running through the points represents a manual graph of the computer fitted data (50). Inset $B$ represents the total range of added and bound ${ }^{125} \mathrm{I}-\mathrm{HMWK}$ in this experiment from which the saturable binding curve was derived.

specific binding increased to be a higher percentage of the total. Fig. 8, inset $B$, the total range of added and bound ${ }^{125} \mathrm{I}-\mathrm{HMWK}$ for this experiment is given. Although points determined up to $2 \mu \mathrm{g} / \mathrm{ml}(16.6 \mathrm{nM})$ of added ${ }^{125} \mathrm{I}-\mathrm{HMWK}$ appeared to give a curve that approached a plateau, point values $>2 \mu \mathrm{g} / \mathrm{ml}(16.6$ $\mathrm{nM}$ ) of added ${ }^{125} \mathrm{I}$-HMWK did not demonstrate a leveling-off of binding. The points from this concentration-dependent experiment were then plotted on a bound-vs.-log free graph (Fig. 8 , inset $A$ ). The sigmoid curve depicted on this graph delineated one binding site which was saturated at $\sim 10 \mathrm{nM}(1.2 \mu \mathrm{g} / \mathrm{ml})$ of added ${ }^{125} \mathrm{I}-\mathrm{HMWK}$. Using the graphical method of Scatchard (42), the saturable binding site appeared to be one of high affinity with an apparent $K_{d}$ of $1.39 \mathrm{nM}$. Confirmation of this interpretation of the graphical representation of the experimental data was obtained by computer $(44,45)$ analysis of the same experiment. Whether a one-site or two-site model for calculation was used, one high affinity site was described with an apparent $K_{d}$ of $0.44 \mathrm{nM}$ and 1,600-1,700 binding sites per platelet. Thus, there was reasonable agreement between the methods of analysis.

Fig. 9 is a graph of the computer fitted points from six individual experiments on unstimulated platelets with concentrations between 1 and $100 \mathrm{nM}$ of free ${ }^{125} \mathrm{I}-\mathrm{HMWK}$. As can be seen, a sigmoid curve was described with a plateau at $\sim 12 \mathrm{nM}$.

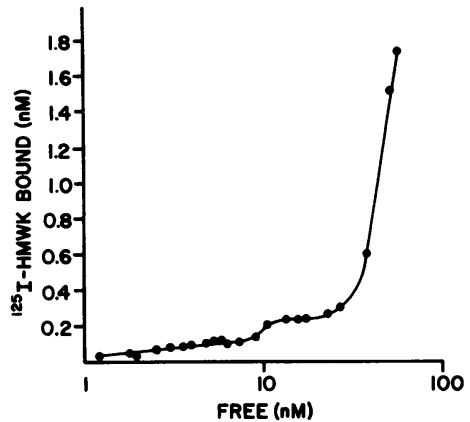

Figure 9. Computer-fitted binding isotherm of ${ }^{125} \mathrm{I}$ HMWK platelet binding to unstimulated platelets. Computer-fitted data points from six experiments performed at $10 \mathrm{~min}$ with a concentration of free ${ }^{125} \mathrm{I}$ HMWK between 1 and 100 $\mathrm{nM}$ were plotted on the abscissa and the bound ${ }^{125} \mathrm{I}$ HMWK (nM) was plotted on the ordinate. The line

running through the points is manually drawn through the computerfitted values.

This plateau characterized one saturable binding site with an apparent $K_{\mathrm{d}}$ of $0.46 \pm 0.19 \mathrm{nM}($ mean $\pm \mathrm{SD})$ and $2,198 \pm 1,036$ molecules per platelet (range, 1,626-3,855 molecules per platelet). Whether a one-site or two-site model was used for calculating the data, this high affinity binding site (apparent $K_{\mathrm{d}}, 0.46 \mathrm{nM}$ and $0.38 \mathrm{nM}$, respectively) was described. This finding validated the description of the high affinity binding site. Using the graphical method of Scatchard, the mean \pm SD of the apparent $K_{d}$ for these same six experiments was $0.99 \pm 0.34 \mathrm{nM}$ with $3,313 \pm 843$ molecules per platelet.

\section{Discussion}

The demonstration that HMWK specifically binds to unstimulated platelets suggests that the platelet surface may contain a discrete receptor for HMWK on its external membrane. Three approaches were used to show that the platelets used in the binding studies were unstimulated. Firstly, ${ }^{125}$ I-HMWK-platelet binding was similar when platelets were washed by centrifugation in the presence of inhibitors as when they were gel filtered. Secondly, ${ }^{125}$ I-HMWK platelet binding was the same to gel-filtered platelets prepared in the presence or absence of $2 \mu \mathrm{M} \mathrm{PGE}_{1}$. Lastly, gel-filtered platelets did not express the PADGEM antigen on their surface by immunofluorescence. The specificity of ${ }^{125} \mathrm{I}$ HMWK-platelet binding is shown by a number of approaches. Trapping of unbound HMWK between cells in the pellet is excluded by ${ }^{125}$ I-albumin studies which show only $0.2 \%$ of radioactivity with the pellet vs. $\geq 1.0 \%$ for the ${ }^{125}$ I-HMWK-platelet interaction. ${ }^{125} \mathrm{I}-\mathrm{HMWK}$-platelet binding in the presence of $\geq 50$ fold molar excess of unlabeled HMWK is $<30 \%$ of the total binding. Moreover, radiolabeled HMWK competes with equal affinity with unlabeled HMWK for platelet binding (Fig. 5) and excess unlabeled HMWK competitively inhibits ${ }^{125}$ I-HMWKplatelet binding (Fig. 6). Finally, only unlabeled HMWK, not PK, Factor XII, Factor XI, Factor V, fibronectin, or fibrinogen (Table I), is able to block ${ }^{125}$ I-HMWK-platelet binding.

Binding of HMWK to unstimulated platelets has an essential divalent cation requirement of zinc (Figs. 3 and 4). Neither calcium nor magnesium contribute anything to the binding of ${ }^{125} \mathrm{I}-$ HMWK to unstimulated platelets since in the absence of these divalent cations, but in the presence of zinc ion, ${ }^{125} \mathrm{I}-\mathrm{HMWK}$ specifically binds to platelets (Fig. $4 B$ ). Using unstimulated platelets, the optimal $\mathrm{Zn}^{++}$concentration for ${ }^{125}$ I-HMWK platelet binding is $50 \mu \mathrm{M}$ (Fig. 3), which is the plasma concentration of zinc (46). Zinc concentrations greater than $200 \mu \mathrm{M}$ inhibit ${ }^{125}$ I-HMWK binding to unstimulated platelets (Fig. 3). This 
finding explains why Greengard and Griffin (19), using $500 \mu \mathrm{M}$ zinc ion, did not see substantial binding of ${ }^{125}$ I-HMWK to unstimulated platelets. Since $\mathrm{Zn}^{++}$has not been shown to be an essential divalent cation for binding of other proteins to platelets, the effect of zinc in HMWK-platelet binding may be on the HMWK molecule and not on the platelets. $50 \mu \mathrm{M}$ zinc ion induces a conformational change of bovine HMWK and its light chain as measured by scanning absorption spectrophotometry (47). Zinc ions (50-100 $\mu \mathrm{M}$ ) also accelerate PK and Factor XII activation by Factor XIIa and kallikrein, respectively, in the presence of sulfatides and HMWK (47).

HMWK binding to unstimulated platelets is characterized by one high affinity, saturable site with an apparent $K_{\mathrm{d}}$ of 0.46 $\pm 0.19 \mathrm{nM}$ by computer fitting of the experimental points in six experiments (Fig. 9) $(44,45)$. The estimated $K_{d}$ determined from the midpoint of fitting the points of the competition inhibition curves from three experiments (Fig. 6) on a four-parameter logistic function (40) and using the midpoint to determine the apparent $K_{\mathrm{d}}$ of binding (41) is found to be similar $\left(K_{\mathrm{d}}, 0.52 \mathrm{nM}\right)$. Secondly, employing a two-site model for computer analysis of the competition inhibition experiments (45), this high affinity site has an apparent $K_{\mathrm{d}}$ of $0.70 \mathrm{nM}$, which is in agreement with the values found in the concentration-dependent binding experiments. Using the graphical methods of Scatchard (42) to analyze the experimental data of this high affinity site on unstimulated platelets, the mean of the apparent $K_{\mathrm{d}}$ in six experiments is found to be similar, $0.99 \pm 0.35 \mathrm{nM}$.

HMWK binding to unstimulated platelets may have a role in the activation of Factor XI. Plasma Factor XI circulates in complex with plasma HMWK (48) and plasma HMWK's adsorption to surfaces is coordinated with the presence of Factor XIIa (49). Since plasma HMWK functions as a cofactor for the surface activation of Factor XII, PK and Factor XI (50), HMWK bound to platelets could provide a locus for these reactions. Given the affinity and number of binding sites for Factor XI (apparent $K_{\mathrm{d}}, 10 \mathrm{nM}, 1,500$ sites/platelet) (51) and Factor XIa (apparent $K_{\mathrm{d}}, 3.25 \mathrm{nM}, 225$ sites/platelet) (52), HMWK binding to unstimulated platelets could provide a sufficient number of platelet sites to support the binding of these proteins to platelets. Since the apparent $K_{d}$ for HMWK-platelet binding is similar to that determined for Factor XI- or XIa-platelet binding, and both of these proteins require HMWK in order to bind to platelets, HMWK (plasma or platelet) may be the platelet receptor for these proteins. Coordinate binding studies are needed to clarify whether HMWK is the platelet receptor for Factors XI and XIa. In conclusion, the finding that ${ }^{125}$ I-HMWK binds with high affinity to the unstimulated platelet suggests that in vivo, the platelet surface may function as a physiological negatively charged surface for the localization of the proteins of the Hageman factor pathways. It remains for further studies to determine whether contact activation on the platelet surface promotes or inhibits intrinsic coagulation or platelet activation.

\section{Acknowledgments}

We would like to thank Dr. Mark Ginsberg and Dr. Lawrence F. Brass for their assistance with the computer programs used for data analysis; Dr. June Wencel-Drake and Dr. Alan Gewirtz for their advice on immunofluorescence; Dr. Barbara Furie and Dr. Cindy Berman for providing antiserum to PADGEM; Ms. Pat Pileggi for preparation of the manuscript; Ms. Monica Kollmann for aid in radiolabeling; Paulette $\mathbf{M}$. Smith and Anthony Farber for technical assistance; Dr. Jerome Gabriel for his advice on atomic absorption spectroscopy; and Dr. Robert W. Colman for his support.

This work was supported in part by a National Heart, Lung, and Blood Institute Fellowship, F32 HL06940 (Dr. Gustafson); a Southeastern Pennsylvania American Heart Association Fellowship Award (Dr. Gustafson); and National Heart, Lung and Blood Institute Clinical Investigator's Award No. HL00694 (Dr. Schmaier); American Heart Association Grant-In-Aid No. 81725 (Dr. Schmaier); an American Heart Association Allegheny Mountain Pennsylvania Chapter Grant-In-Aid (Dr. Schmaier); and the Ben Franklin Partnership of the State of Pennsylvania (Dr. Schmaier).

\section{References}

1. Ratnoff, O. D., and J. M. Rosenblum. 1958. Role of Hageman factor in the initiation of clotting by glass. Evidence that glass frees Hageman factor from inhibition. Am. J. Med. 25:160-169.

2. Cochrane, C. G., S. D. Revak, and K. D. Wuepper. 1973. Activation of Hageman factor in solid and fluid phases. A critical role of kallikrein. J. Exp. Med. 138:1564-1583.

3. McMillan, C. R., H. Saito, O. D. Ratnoff, and A. G. Watson. 1974. The secondary structure of human Hageman Factor (Factor XII) and its alteration by activating agents. J. Clin. Invest. 54:1312-1322.

4. Revak, S. D., C. G. Cochrane, and J. H. Griffin. 1977. The binding and cleavage characteristics of human Hageman factor during contact activation. A comparison of normal plasma with plasma deficient in Factor XI, prekallikrein, or high molecular weight kininogen. J. Clin. Invest. 58:1167-1175.

5. Griffin, J. H. 1978. The role of surface in the surface-dependent activation of Hageman factor (blood coagulation factor XII). Proc. Natl. Acad. Sci. USA. 75:1998-2002.

6. Ratnoff, O. D., and H. Saito. 1979. Amidolytic properties of singlechain activated Hageman factor. Proc. Natl. Acad. Sci. USA. 76:14611463.

7. Wiggins, R. C., and C. G. Cochrane. 1979. The autoactivation of rabbit Hageman factor. J. Exp. Med. 150:1122-1133.

8. Miller, G., M. Silverberg, and A. P. Kaplan. 1980. Autoactivability of human Hageman factor. Biochem. Biophys. Res. Commun. 92:803810.

9. Silverberg, M., J. T. Dunn, L. Garen, and A. P. Kaplan. 1980. Autoactivation of human Hageman factor. Demonstration utilizing a synthetic substance. J. Biol. Chem. 255:7281-7286.

10. Kirby, E., and P. J. M. McDevitt. 1983. The binding of bovine factor XII to kaolin. Blood. 61:652-659.

11. Tankersky, D. L., and J. S. Finlayson. 1984. Kinetics of activation and autoactivation of human factor XII. Biochemistry. 23:273-279.

12. Ratnoff, O. D. 1966. The biology and pathology of the initial coagulation. In Progress in Hematology, Vol. V. E. G. Brown and C. V. Moore, editors. Grune and Stratton, Inc., New York. 204-245.

13. Harpel, P. C. 1972. Studies on the interaction between collagen and a plasma kallikrein-like activity. Evidence for a surface-active enzyme system. J. Clin. Invest. 51:1813-1822.

14. Fujikawa, K., R. L. Heimark, K. Kurachi, and E. W. Davie. 1980. Activation of bovine factor XII (Hageman factor) by plasma kallikrein. Biochem. J. 19:1322-1330.

15. Tans, G., J. Rosing, and J. H. Griffin. 1983. Sulfatide-dependent autoactivation of human blood coagulation factor XII (Hageman factor). J. Biol. Chem. 258:8215-8222.

16. Hojima, V., C. G. Cochrane, R. C. Wiggins, K. F. Austen, and R. L. Stevens. 1984. In vitro activation of the contact (Hageman factor) system of plasma by heparin and chondroitin sulfate. Blood. 63:14531459.

17. Schmaier, A. H., A. Zuckerberg, C. Silverman, J. Kuchibhotla, G. P. Tuszynski, and R. W. Colman. 1983. High molecular weight kininogen: a secreted platelet protein. J. Clin. Invest. 71:1477-1489.

18. Schmaier, A. H., P. M. Smith, and R. W. Colman. 1986. High 
molecular weight kininogen: localization in unstimulated and activated platelets and activation by a platelet calpain(s). Blood. 67:119-130.

19. Greengard, J. S., and J. H. Griffin. 1984. Receptors for high molecular weight kininogen on stimulated washed human platelets. Biochemistry. 23:6863-6869.

20. Molnar, J., and L. Lorand. 1961. Studies on apyrase. Arch. Biochem. Biophys. 93:353-363.

21. Schmaier, A. H., W. Claypool, and R. W. Colman. 1980. Crotalocytin: recognition and purification of a timber rattlesnake platelet aggregating protein. Blood. 56:1013-1019.

22. Kerbiriou, D. M., and J. H. Griffin. 1979. Human high molecular weight kininogen. Studies of structure-function relationships and of proteolysis of the molecule occurring during contact activation of plasma. J. Biol. Chem. 254:12020-12027.

23. Laemmli, U. K. 1970. Cleavage of structural proteins during the assembly of the head of bacteriophage $\mathrm{T}_{4}$. Nature (Lond.). 227:680-685.

24. Fraker, P. J., and S. C. Speck, Jr. 1978. Protein and cell membrane iodinations with a sparingly soluble chloroamide 1,3,4,6-tetrachloro-3 alpha, 6 alpha-diphenylglycoluril. Biochem. Biophys. Res. Commun. 80: 849-857.

25. Scott, C., C. Y. Liu, and R. W. Colman. 1979. Human plasma prekallikrein: a rapid high-yield method for purification. Eur. J. Biochem. 100:77-823.

26. Bradford, M. M. 1976. Rapid and sensitive method for the quantification of microgram quantities of protein utilizing the principle of protein-dye binding. Anal. Biochem. 72:248-254.

27. Colman, R. W., A. Bagdasarian, R. C. Talamo, C. F. Scott, M. Seavy, J. A. Guimares, J. V. Pierce, and A. P. Kaplan. 1975. Williams trait. Human kininogen deficiency with diminished levels of plasminogen proactivator and prekallikrein associated with abnormalities of the Hageman-dependent pathways. J. Clin. Invest. 56:1650-1662.

28. Bagdasarian, A., B. Lahiri, R. C. Talamo, P. Wong, and R. W. Colman. 1974. Immunochemical studies of plasma kallikrein. J. Clin. Invest. 54:1444-1454.

29. Mancini, G. A., A. O. Carbonara, and J. F. Heremans. 1964. Immunochemical quantification of antigens by single radial immunodiffusion. Immunochemistry. 22:235-245.

30. Fisher, C. A., A. H. Schmaier, V. P. Addonizio, and R. W. Colman. 1982. Assay of plasma prekallikrein: comparison of amidolytic, esterolytic, coagulation and immunochemical assays. Blood. 59:963-970.

31. Schmaier, A. H., and R. W. Colman. 1980. Crotalocytin: characterization of the timber rattlesnake platelet-activating protein. Blood. 56:1020-1028.

32. Timmons, S., and J. Hawiger. 1978. Separation of human platelets from plasma proteins including factor VIII vwf $_{\text {by a combined albumin }}$ gradient-gel filtration method using Hepes buffer. Thromb. Res. 12:297306.

33. Mustard, J. F., D. W. Perry, N. H. Ardlie, and M. A. Packham. 1972. Preparation of suspensions of washed platelets from humans. $B r$. J. Haematol. 22:193-204.

34. Wencel-Drake, J. D., E. F. Plow, T. S. Zimmerman, R. G. Painter, and M. H. Ginsberg. 1984. Immunofluorescent localization of adhesive glycoproteins in resting and thrombin-stimulated platelets. Am. J. Physiol. 115:156-164.

35. Harfenist, E. J., M. A. Guccione, M. A. Packham, and J. F.
Mustard. 1982. The use of the synthetic peptide Gly-Pro-Arg-Pro, in the preparation of thrombin degranulated platelets. Blood. 59:952-955.

36. Mazur, E. M., R. Hoffman, J. Chasis, S. Marchesi, and E. Bruno. 1981. Immunofluorescent identification of human megakaryocyte colonies using an anti-platelet glycoprotein antiserum. Blood. 57:277-286.

37. Hsu-Lin, S-C, C. L. Berman, B. C. Furie, D. August, and B. Furie. 1984. A platelet membrane protein expressed during platelet activation. J. Biol. Chem. 259:9121-9126.

38. Berman, C. L., E. L. Yeo, J. Wencel-Drake, B. C. Furie, M. H. Ginsberg, and B. Furie. 1985. A platelet alpha granule membrane protein that is incorporated into the plasma membrane during activation. Clin. Res. 33:544a. (Abstr.).

39. DeLean, A., A. A. Hancock, and R. J. Lefkowitz. 1982. Validation and statistical analysis of a computer modeling method for quantitative analysis of radioligand binding data for mixtures of pharmacological receptor subtypes. Mol. Pharmacol. 21:5-16.

40. Canellas, P. F., and A. E. Karu. 1981. Statistical package for analysis of competitive ELISA results. J. Immunol. Methods. 47:375385.

41. Muller, R. 1983. Determination of affinity and specificity of antiHapten antibodies by competitive radioimmunoassay. Methods Enzymol. 92:589-601.

42. Scatchard, G. 1949. The attraction of proteins for small molecules and ions. Ann. NY Acad. Sci. 51:660-672.

43. Klotz, I. M. 1982. Number of receptor sites from Scatchard graphs: facts and fantasies. Science (Wash. DC). 217:1247-1249.

44. Munson, P. J., and D. Rodbard. 1980. LIGAND: a versatile computerized approach for characterization of ligand-binding systems. Anal. Biochem. 107:220-239.

45. Brass, L. F., and S. J. Shattil. 1982. Changes in surface-bound and exchangeable calcium during platelet activation. J. Biol. Chem. 257: 14000-14005.

46. Foley, B., S. A. Johnson, B. Hackley, J. C. Smith, Jr., and J. A. Halsted. 1968. Zinc content of human platelets. Proc. Soc. Exp. Biol. Med. 128:265-269.

47. Shimada, T., H. Kato, and S. Iwanaga. 1984. Effect of metal ions on the surface-mediated activation of factor XII and prekallikrein. In Kinins '84. L. Greenberg, editor. Conference at Savannah, GA. (Abstr.).

48. Thompson, R. E., R. Mandle, Jr., and A. P. Kaplan. 1977. Association of factor $\mathrm{XI}$ and high molecular weight kininogen in human plasma. J. Clin. Invest. 60:1376-1380.

49. Scott, C. F., L. D. Silver, M. Schapira, and R. W. Colman. 1984. Cleavage of human high molecular weight kininogen markedly enhances its coagulant activity. Evidence that this molecule exists as a procofactor. J. Clin. Invest. 73:954-962.

50. Silverberg, M., J. E. Nicoll, and A. P. Kaplan. 1980. The mechanisms by which the light chain of cleaved HMW-kininogen augments the activation of prekallikrein, factor XI and Hageman factor. Thromb. Res. 20:173-189.

51. Greengard, J. S., M. J. Heeb, E. Ersdal, P. N. Walsh, and J. H. Griffin. 1986. Binding of factor XI to human platelets. Biochemistry. In press.

52. Sinha, D., F. S. Seaman, A. Koshy, L. C. Knight, and P. N. Walsh. 1984. Blood coagulation factor XIa binds specifically to a site on activated human platelets distinct from that for factor XI. J. Clin. Invest. 73:1550-1556. 